\title{
AN EMPIRICAL STUDY OF THE IMPACT OF EMOTIONS AND PERSONALITY ON SOCIAL NETWORKING
}

\author{
Alan R. Peslak, Penn State University, arp14@psu.edu \\ Neelima Bhatnagar, University of Pittsburgh Johnstown, bhatnagr@pitt.edu
}

\begin{abstract}
Social networking is the use of Internet and communications technologies to build human relationships between individuals via sharing and exchange of personal information over designated web sites and services such as Facebook and Twitter. The explosion in popularity of Social Networking over the past several years has resulted in a remarkable increase in Internet usage among the general population. Understanding how this technology is affected by human emotions and personality can help us understand how and why this technology has been so successful in enhancing human communications. Our study found that higher levels of introversion lead to higher likelihood of Social Networking use. However, higher levels of extraversion lead to higher frequency of Social Networking activity. Surprisingly, there are no positive emotions that influence whether someone uses social networking or not. Three emotions do correlate with use, but in a negative fashion. The amount of time people spend on social networking is positively related to being enthusiastic and proud and not being irritated or disappointed. Finally, we examine how often people visit social networking sites. Frequency of visits is related to enthusiasm and lack of disappointment. Gender and age correlations are also discussed.
\end{abstract}

Keywords: Social Networking, Emotions, Personality, Behavior, Communication, Gender, Age

\section{INTRODUCTION}

The social networking phenomenon is a fairly recent one having gained widespread recognition in the past 8 years. Social networking is also referred to as social networking services, social media, computer mediated communication, and online social networking. According to Kwon and Wen [12], social network services can be defined as "an individual web page which enables online, human-relationship building by collecting useful information and sharing it with specific or unspecific people." More specifically, social network sites, according to Boyd and Ellison [5], are "...web-based services that allow individuals to (1) construct a public or semi-public profile within a bounded system, (2) articulate a list of other users with whom they share a connection and (3) view and traverse their list of connections and those made by others within the system." According to AmichaiHamburger, Wainapel, and Fox "social communication is one of the most common reasons for using the Internet." [3].

\section{AGE AND GENDER DIFFERENCES IN SOCIAL NETWORKING USE}

Early studies and research on Internet usage focused on gender and age differences. According to Weiser [24], the Internet had always been viewed as a high-tech tool made solely for men by men. Weiser further elaborates that females tended to view the Internet as a tool for "...interpersonal communication and, to a lesser extent, academic assistance; in contrast, male use [was] driven mainly by entertainment and leisure." [24]. Weiser conducted two studies to compare gender differences in the use of the Internet. In the first study, a survey was posted online for users to complete. The second survey, completed by hand, was administered to college freshmen. His findings, as he expected, were similar to conclusions drawn in previous studies: that females found using the Internet (for email, and personal interactions) more attractive than males. In the book titled 'Different Voice' by Carol Gilligan, the author "....argued that differences in socialization lead to gender differences in identity, with female identity revolving around interconnectedness and relationship and male identity stressing separation and independence." [14]. Morahan-Martin further identifies many reasons for the differences between Internet use by men and women. These include: "related computer attitudes; Internet ethics; linguistic differences between men and women; pathological Internet use; and the masculine, technological mystique surrounding the Internet all contribute to women using the Internet less than do men." [14]. This may partly be because of the fact that men are exposed to computers and become adept at using them at an early age which also explains their positive attitudes towards 
computers compared to females [14]. The exposure to computers at an early age may also be a reason for the maledominated Internet world [14]. A study conducted by Teo \& Lim [22] in Singapore revealed that Internet users were primarily male between 16-25 years of age. Females only accounted for $11 \%$ of the total number of Internet users (based on the number of responses received). They draw similar conclusions for the differences in technology use by men and women. Men have been typically viewed as being technology savvy and having no fear of using computers, therefore being more inclined to use the Internet mostly to seek additional information pertaining to technology. They also suggest that female presence on the Internet may be low due in part to intimidation by males, as well as few Internet sites geared towards females. Overall, they arrive at the same conclusion as Weiser in that females use the Internet for communication purposes. Teo [21] in his article makes reference to a study conducted by Broos (in 2005) which indicated that males were more excited when facing new technologies and had a positive attitude towards them sooner, whereas females took longer to become comfortable and accept new technology therefore taking longer to view the technology in a positive way.

According to Weiser [24], before 1995 when the Internet "began to permeate the cultural landscape, fewer than 20 million people worldwide used the Internet regularly.” The demographics today, in terms of the diffusion of the Internet around the world have changed drastically. Oceania/Australia and North America have experienced the largest diffusion with $61.3 \%$ and $77.4 \%$, respectively, of the total population using the Internet. The diffusion of the Internet in the remaining regions of the world is as follows: Africa 10.9\%, Asia 21.5\%, Middle East 29.8\%, Latin America/Caribbean 34.5\%, and Europe $58.4 \%$ [25]. With the rise in growth and popularity of the Internet, more recent studies and statistics reveal a reversal in gender differences as far as Internet use is concerned. Today, women represent a larger number of Internet users than men. As of last year, Facebook had 500 million users worldwide. Seventy percent of the users reside outside the United States; $46 \%$ of the users are male and $54 \%$ are female. In comparison, Twitter had 106 million users, with men representing $48 \%$ of the users and female $52 \%$. Sixty percent of Twitter users reside outside of the United States [23].

Odell, Korgen, Schumacher, and Delucchi [15] conducted research among college students and also found that the gap between male and female use of the Internet was narrowing. They surveyed college students, since the 18-29 year olds continue to be the largest group of Internet users. According to the most recent Pew Research Center survey conducted in May 2010, this group accounts for 95\% of the Internet users today [27]. According to the latest Nielsen Wire, social networks, online games, and email represent the top three sectors in terms of time spent on the Internet. Social networks account for 22.7\%, online games $10.2 \%$, and email 8.3\% [26].

One of the first widely recognized social networking sites was SixDegrees.com, launched in 1997 [5]. However, Friendster (launched in 2002), MySpace (launched in 2003), and Facebook (initially launched in 2004), can be considered to be the social networking sites that defined the areas of business, popular culture, and research [5]. Some of the most popular social networking sites on the Internet today are: Facebook, Twitter, LinkedIn, and MySpace (ranked $1^{\text {st }}, 2^{\text {nd }}, 3^{\text {rd }}$, and $4^{\text {th }}$ respectively), among others [18]. Twitter was launched in 2006; LinkedIn and MySpace were launched in 2003 [5]. According to Ross, Orr, Sisic, Arseneault, Simmering, and Orr, Facebook has become "...one of the most popular tools for social communication." [19].

\section{LITERATURE REVIEW OF EMOTIONS AND EFFECT ON BEHAVIOR AND COMMUNICATION}

A person's age and gender aren't the only factors that influence or impact social media use. It also has very much to do with emotions and their impact on a person's behavior and subsequent communication. According to Allen, Machleit and Kleine "...emotions serve as primary motivators of behavior..." [1]. Humans are after all "emotional creatures..." [6]. Brown [6] also states that "feelings and moods affect our attitudes, motivation, behaviors, and interactions with people around us virtually all our waking hours.” Furthermore, he elaborates on Goleman's 1995 book titled "Emotional Intelligence, which talks about humans having two minds: an emotional one and a rational one. It is the emotional one that affects our behaviors. It is "...our temperament and moods [that] predispose us to experience certain emotions more readily than others." [6]. Emotions and feelings play an important role in determining people's willingness to accept new technologies [16]. From a psychological standpoint, negative emotions are present in new technology situations more often than positive emotions. Perlusz [16] argues that the need to study the affects of positive feelings are as important as studying negative feelings when it comes to 
technology acceptance, because positive feelings towards technology (i.e. social networking) are also important when it comes to determining behaviors. Affects are“...positive and negative sentiments, emotions, feelings and moods that are experienced in many different circumstances and have an influence in the way we reason and make decisions. Affects can be stable characteristics of the personality (i.e., a trait) or may be experienced in particular moments (i.e., a state).” [16]. In a survey of undergraduate students, Perlusz [16] found that: “...(1) NA [Negative affect] and PA [positive affect] are distinguishable dimensions of technology-related affect; (2) affect exerts a low influence when a subject is experiencing negative emotions; (3) both PA [positive affect] and NA [negative affect] are significant predictors of acceptance, when a subject is experiencing positive emotions" [16].

The Technology Acceptance Model is widely known among IS researchers. According to Gefen and Keli [9], "The Technology Acceptance Model (TAM) suggests that the perceived usefulness (PU) and the perceived ease of use (PEOU) of an information system (IS) are major determinants of its use." Furthermore, "PU can be defined as "the degree to which a person believes that using a particular system would enhance his or her job performance" (Davis, 1989, p.320) while PEOU is the "the degree to which a person believes that using a particular system would be free of effort." (Davis, 1989, p. 320)" [9]. However TAM falls short in attempting to explain the "role of emotions in technology acceptance..." [4]. Bagozzi [4] argues that "for instance, intrinsic motivation, affect toward use, (joy versus sadness emotions), affect (liking for a particular behavior), and anxiety toward performing a behavior have been proposed as direct predictors of effort and/or performance expectations and, therefore, are claimed to be indirect determinants of intentions (Venkatesh, 2000; Venkatesh et al., 2003, Figure 3)”

Despite all of the studies done to measure the interconnectedness of emotions and behaviors to new technology situations, Lyons supposes that the outward behavior is not always a good indicator of emotion. According to Lyons [13], "...there is another factor which partly explains why it is hard to predict exactly what sort of behavior will result even from emotions which have specifiable want or appetitive aspects.” That factor has very much to do with the fact that "... without knowing a great deal about the object of the emotion in question, one cannot get very far in predicting what sort of behavior will result from that emotion.” [13]. He goes on to say that "...we do look upon behavior as an 'external' state or public indicator of 'inner' or private states, such as the beliefs, appraisals, and in particular the wants aspects of emotions.” [13]. However, “...behavior as well is associated with an emotion only insofar as it is believed that the behavior is caused, indirectly, by the beliefs and evaluations (or appraisals) which make up the cognitive elements of the emotions in question, and, proximately or directly, by the wants which make up the appetitive elements of such emotions.” [13].

\section{LITERATURE REVIEW OF EFFECT OF PERSONALITY ON BEHAVIOR AND COMMUNICATION}

Much like traditional social interactions are influenced by an individual's personality, so, too, does personality “...affect[s] an individual's choice of online or offline means for conducting social interactions.” [10]. Goby surveyed college students in Singapore and found that extraverts prefer social interactions offline as compared to introverts. This also means that an individual's personality has a considerable influence as to how inclined they are to accept online modes of communication. There is a strong correlation between personality type, attitudes, and the method people choose to use for social networking, both online as well as offline [10]. Personality also determines online behavior. Amichai-Hamburger has done extensive research on personality types and social networks suggesting that "... personality is a leading factor in understanding why people behave the way they do on the Internet." [2]. The connection between personality and Internet use has been established using the following personality theories: extraversion, neuroticism, need for closure, and sensation seeking [2]. Therefore it can also help explain the link between personality and online social networking. According to Harbaugh [11], "... personality traits influence peoples' motivation and behavior during social interaction, both online and offline." Extraverts " $\ldots$ tend to be lively, assertive, active, carefree, outgoing, and enjoy surrounding themselves with others mainly, while those lower in the extraversion trait are more likely to be shy, introspective and less likely to seek external social stimulation. The extravert also desires excitement, takes risks and acts impulsively at times, while the introvert is a quiet, reflective person who prefers time alone, does not crave excitement and can be seen as distant by others at times." [11].

Other important research findings mentioned in the Harbaugh [11] article include: 
- Extraverts having more positive and favorable encounters online than introverts

- Extraverts use social media repeatedly because they are successful

- Extraverts use social media routinely given that two-thirds of the population is composed of extraverts and the remaining one-third are introverts; therefore extraverts would also use social networking sites more extensively than introverts

- Personality is a major determinant of how we behave online

- Both introverts and extraverts feel satisfied and benefit from being able to communicate and have interactions with others in an online environment

Past researchers (Amichai-Hamburger \& Vinitzky [2]) have used the Five-factor model to study the importance of personality traits on Internet use. The Five-factor model includes: extraversion, neuroticism, openness to expression, agreeableness, and conscientiousness. Each of these factors can be defined as follows:

- Neuroticism - Neuroticism is defined as “.... person’s tendency to experience psychological distress and high levels of this trait are associated with a sensitivity to danger" [2].

- Extraversion - “...reflects a tendency to be sociable and able to experience positive emotions” [2].

- Openness to experience - “...represents an individual's willingness to consider alternative approaches, be intellectually curious, and enjoy artistic pursuits” [2].

- Agreeableness - “...tendency to be trusting, sympathetic, and cooperative” [2].

- Conscientiousness - “...reflects the degree to which an individual is organized, diligent, and scrupulous" [2].

Extraversion, neuroticism, and openness to experience seemed to be better predictors in explaining the connection between personality type and the use of social networking site [7]. Correa, Hinsley and Zuniga [7] conducted an online survey among adults between 2008-2009 to determine if extraverts use social networking more regularly than introverts and whether or not personality and social media use is different based on gender. Here are some of the conclusions they draw, based on the survey that was conducted:

- “...people with high levels of extraversion tend to be more emotionally stable and open to new experiences" [7]

- “...people who are more extraverted will use social media more frequently...” [7]

- "For men, extraversion was positively related to social media use" [7]

- " "For women, extraversion and openness to experience were positively related to social media use" [7]

- "Women with higher levels of extraversion and openness tend to use social media more frequently" [7]

- Current social media applications aren’t anonymous therefore extraverted people tend to engage more in social media use [7]

Amichai-Hamburger \& Vinitzky [2] also state that “...personality is a leading factor in understanding why people behave the way they do on the Internet." Previous research conducted by Amichai-Hamburger et al. predicted that extraverts would "(a) demonstrate more frequent use of Facebook; (b) make greater use of Facebook components for communication; (c) have more Facebook friends; and (d) belong to more Facebook groups.” [2].

\section{MOTIVATION FOR THE STUDY}

Social networking has become one of the most important and fastest growing methods of communication today. It is important to understand the motivations and issues associated with this technology. Past studies of social networking have focused on single areas of social media, personality, or emotions. One study examined the effect of personality on use of social media. However, it did not study only social networking. Included was instant messaging. In this study published by Correa, Hinsley and Zuniga [7], a construct was measured by an additive scale that calculated the frequency of usage of the following applications: instant messages and social networking sites. On a 10-point response scale, respondents were asked how often they use the Internet for instant messaging and social networking sites, where 1 was rarely/never and 10 was often, $r=.41, \mathrm{p}<.001(\mathrm{M}=8.03$, SD $=5.79)$. We believe that combining instant messaging and social networking may have biased the results. This is especially relevant 
considering the rapid decline of instant messaging since 2008. Our study is an attempt to verify the findings of this study specifically and solely for social networking, as well as expand on its analysis. In addition, our study extends this analysis by studying another aspect of social networking that has not been studied before: emotions and social networking and social networking use and behavior as well as studying the impact of gender on social networking use. Our study is firmly based on the preceding literature review of social networking, emotions, gender, age, and extraversion/introversion.

\section{Research Questions}

As a result of the literature review, certain research questions warrant exploration. Correa, Hinsley and Zuniga [7] found that only extraversion contributed to social media use. Previous research has established three personality traits that are central to social media use: extraversion, neuroticism, and openness to experience ([19] and [28]). People who are more open to experiences tend to be drawn to SNS (social networking sites), as are those with high levels of neuroticism. Individuals high in neuroticism, as well as people who are extraverted, also seem to have greater use of instant messages [8]. As a result of this research, we have developed the first research question.

Research Question 1: How do levels of introversion/extraversion affect use of social networking sites?

Shaw [20] and Peslak [17] studied the relationship between specific emotions and particular information activities. This prompts research question two.

Research Question 2: What specific emotions correlate with social networking use?

\section{METHODOLOGY}

A survey was prepared and pretested with groups of students at one northeastern US university. The survey was modified based on preliminary testing and administered to 196 students and faculty at several US universities. The survey was a comprehensive survey of Social Networking Usage and Behavior. A subset of this study included specific questions that developed into this study. As stated previously, extraverts can generally be described as being outgoing and enthusiastic while introverts are generally described as being self-contained and reserved.

The questions explored the following areas:

- How would you classify yourself: Very introverted, Introverted, Somewhat introverted, Neutral, Somewhat extraverted, Extraverted, Strongly extraverted

- I currently use Social networking: Strongly agree, Agree, Somewhat agree, Neutral, Somewhat disagree, Disagree, Strongly disagree

- I experience the following emotions when Social networking - ( for example Calm): Strongly agree, Agree, Somewhat agree, Neutral, Somewhat disagree, Disagree, Strongly disagree

- Please select the closest estimate of how often you use Social networking: Never, Once a Month, Several times per month, Once a week, Several times a Day, Many times a day

- Please select the closest estimate of how much time is spent Social networking each month: 0-5 Minutes, 30 Minutes, 60 Minutes, 3 Hours, 10 Hours, more than 10 hours

To study the correlation of emotions and social networking, a list of 14 emotions was included in the survey. The list was extracted from Shaw [20], Peslak [17] and others. Though no definitive emotions lists exist, the Shaw source coupled with other relevant emotions from the literature review provided a comprehensive mix of positive and negative emotions. Software used in the study was SPSS 17.0 and AMOS 17.

\section{RESULTS}

\section{Research Question 1: How do levels of introversion/extraversion affect use of social networking sites?}


Volume XII, No. 1, pp. 159-169, 2011

Table 1 Currently Use by level of Intro/Extraversion Coefficients ${ }^{a}$

\begin{tabular}{|c|c|c|c|c|c|c|}
\hline \multirow{2}{*}{\multicolumn{2}{|c|}{ Model }} & \multicolumn{2}{|c|}{ Unstandardized Coefficients } & \multirow{2}{*}{\begin{tabular}{|l|}
$\begin{array}{l}\text { Standardized } \\
\text { Coefficients }\end{array}$ \\
Beta \\
\end{tabular}} & \multirow[b]{2}{*}{$\mathrm{T}$} & \multirow[b]{2}{*}{ Sig. } \\
\hline & & B & Std. Error & & & \\
\hline \multirow[t]{4}{*}{1} & (Constant) & 6.232 & .526 & & 11.841 & .000 \\
\hline & Extraverts/Introverts & .213 & .069 & .228 & 3.072 & .003 \\
\hline & Please provide your Gender: & -.541 & .198 & -.206 & -2.736 & .007 \\
\hline & What is your age? & -.250 & .076 & -.246 & -3.306 & .001 \\
\hline
\end{tabular}

a. Dependent Variable: I currently use social networking.

Contrary to Correa, Hinsley and Zuniga [7] who found that extraversion contributed to social media use (including IM and others), we found that when only social networking is included, introversion actually contributes to increased tendency to use social networking at $\mathrm{p}<.003$ (Table 1).

In addition, females use social networking more than males at $\mathrm{p}<.007$ and younger age led to higher levels of social networking usage. All variables studied significantly affected usage.

Table 2 Time Used by level of Intro/Extraversion Coefficients ${ }^{\mathrm{a}}$

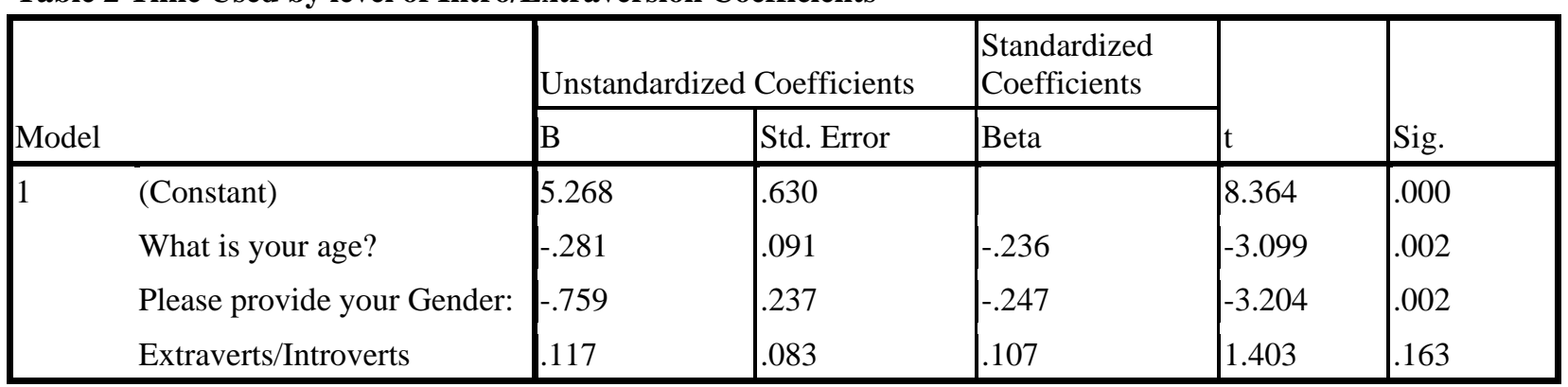

a. Dependent Variable: time

In table 2 we see that younger people spend more time on social networking compared to older individuals, and females spend more time than males. This confirms prior studies. Level of extraversion has no impact on amount of time spent on social networking which again differs with some prior studies.

Table 3 Frequency of Use by level of Intro/Extraversion Coefficients ${ }^{a}$

\begin{tabular}{|c|c|c|c|c|c|c|}
\hline \multirow{2}{*}{\multicolumn{2}{|c|}{ Model }} & \multicolumn{2}{|c|}{ Unstandardized Coefficients } & \multirow{2}{*}{\begin{tabular}{|l}
$\begin{array}{l}\text { Standardized } \\
\text { Coefficients }\end{array}$ \\
Beta \\
\end{tabular}} & \multirow[b]{2}{*}{$\mathrm{t}$} & \multirow[b]{2}{*}{ Sig. } \\
\hline & & B & Std. Error & & & \\
\hline \multirow[t]{4}{*}{1} & (Constant) & 6.185 & .672 & & 9.204 & .000 \\
\hline & What is your age? & -.404 & .096 & -.312 & -4.192 & .000 \\
\hline & Please provide your Gender: & -.651 & .253 & -.194 & -2.568 & .011 \\
\hline & Extraverts/Introverts & .224 & .089 & .188 & 2.526 & .013 \\
\hline
\end{tabular}

a. Dependent Variable: often 
Volume XII, No. 1, pp. 159-169, 2011

In table 3 we see that level of extraversion does affect how often people use social networking (this is different from table 2 in that here we are looking at frequency or how often and in two we are looking at total time). Extraverts use social networking more often than introverts. Females use more often as do younger individuals. Younger individuals use social networking more often than older individuals.

\section{Research Question 2: What specific emotions correlate with social networking use?}

The area of emotions and social networking is important but has been lightly studied. As literature suggests, how people feel about this important social and communication experience can have a large impact on its usage.

Table 4 Currently use and Emotions Coefficients ${ }^{\mathrm{a}}$

\begin{tabular}{|c|c|c|c|c|c|}
\hline \multirow[b]{2}{*}{ Model } & \multicolumn{2}{|c|}{ Unstandardized Coefficients } & \multirow{2}{*}{$\begin{array}{l}\text { Standardized Coefficients } \\
\text { Beta }\end{array}$} & \multirow[b]{2}{*}{$\mathrm{t}$} & \multirow[b]{2}{*}{ Sig. } \\
\hline & B & Std. Error & & & \\
\hline 1 (Constant) & 7.260 & .853 & & 8.508 & .000 \\
\hline Disappointed & .153 & .099 & .150 & 1.541 & .126 \\
\hline Proud & -.064 & .109 & -.052 & -.586 & .559 \\
\hline Uninspired & .082 & .099 & .076 & .824 & .412 \\
\hline Pleased & -.165 & .122 & -.133 & -1.357 & .177 \\
\hline Angry & .070 & .128 & .069 & .541 & .589 \\
\hline Relieved & -.015 & .130 & -.011 & -.119 & .905 \\
\hline Optimistic & .214 & .143 & .150 & 1.499 & .136 \\
\hline Apathetic & -.247 & .116 & -.179 & -2.124 & .036 \\
\hline Worried & .114 & .123 & .115 & .928 & .355 \\
\hline Disgusted & .102 & .127 & .105 & .809 & .420 \\
\hline Calm & .144 & .134 & .108 & 1.075 & .284 \\
\hline Enthusiastic & -.524 & .191 & -.404 & -2.743 & .007 \\
\hline Stimulated & -.057 & .167 & -.044 & -.338 & .736 \\
\hline Irritated & -.258 & .130 & -.251 & -1.985 & .049 \\
\hline
\end{tabular}

a. Dependent Variable: I currently use social networking.

Surprisingly, there are no positive emotions that associated with whether someone uses social networking or not (table 4). Three emotions do correlate with use but in a negative fashion. Users of social networking are less likely to be enthusiastic, irritated, or apathetic. The results suggest perhaps a moderating effect on overall emotional swings both high and low. 
Volume XII, No. 1, pp. 159-169, 2011

Table 5 Time Used and Emotions Coefficients ${ }^{\mathrm{a}}$

\begin{tabular}{|c|c|c|c|c|c|c|}
\hline & & Unstal & oefficients & \begin{tabular}{|l} 
Standardized \\
Coefficients
\end{tabular} & & \\
\hline & & B & Std. Error & Beta & $\mathrm{t}$ & Sig. \\
\hline 1 & (Constant) & 7.444 & .989 & & 7.526 & .000 \\
\hline & Disappointed & .249 & .115 & .214 & 2.164 & .032 \\
\hline & Proud & -.306 & .126 & -.219 & -2.427 & .017 \\
\hline & Uninspired & -.082 & .115 & -.067 & -.717 & .475 \\
\hline & Pleased & .071 & .141 & .050 & .501 & .617 \\
\hline & Angry & .024 & .149 & .021 & .162 & .872 \\
\hline & Relieved & .078 & .150 & .048 & .520 & .604 \\
\hline & Optimistic & -.142 & .165 & -.087 & -.858 & .393 \\
\hline & Apathetic & -.168 & .135 & -.106 & -1.245 & .215 \\
\hline & Worried & .162 & .143 & .142 & 1.138 & .257 \\
\hline & Disgusted & .023 & .147 & .020 & .154 & .878 \\
\hline & Calm & .044 & .155 & .029 & .282 & .778 \\
\hline & Enthusiastic & -.396 & .221 & -.266 & -1.788 & .076 \\
\hline & Stimulated & -.207 & .194 & -.139 & -1.065 & .289 \\
\hline & Irritated & -.304 & .151 & -.258 & -2.018 & .046 \\
\hline
\end{tabular}

a. Dependent Variable: time

The next analysis was based on measuring emotions and the amount of time spent on social networking. In this study we do have some positive relationships. People who feel proud and enthusiastic while social networking will spend more time social networking than others at $\mathrm{p}<.10$. In addition, those who are irritated will spend more time social networking, perhaps communicating their irritation. Those who are disappointed however, will spend less time social networking. Both of these correlations are significant at $\mathrm{p}<.05$. Certain emotions are correlated with the amount of time people spend on social networking sites.

Finally, we examine how often people visit social networking sites. Frequency of visits is related to enthusiasm and not being disappointed. 
Volume XII, No. 1, pp. 159-169, 2011

Table 6 Frequency of Use and Emotions Coefficients ${ }^{\mathrm{a}}$

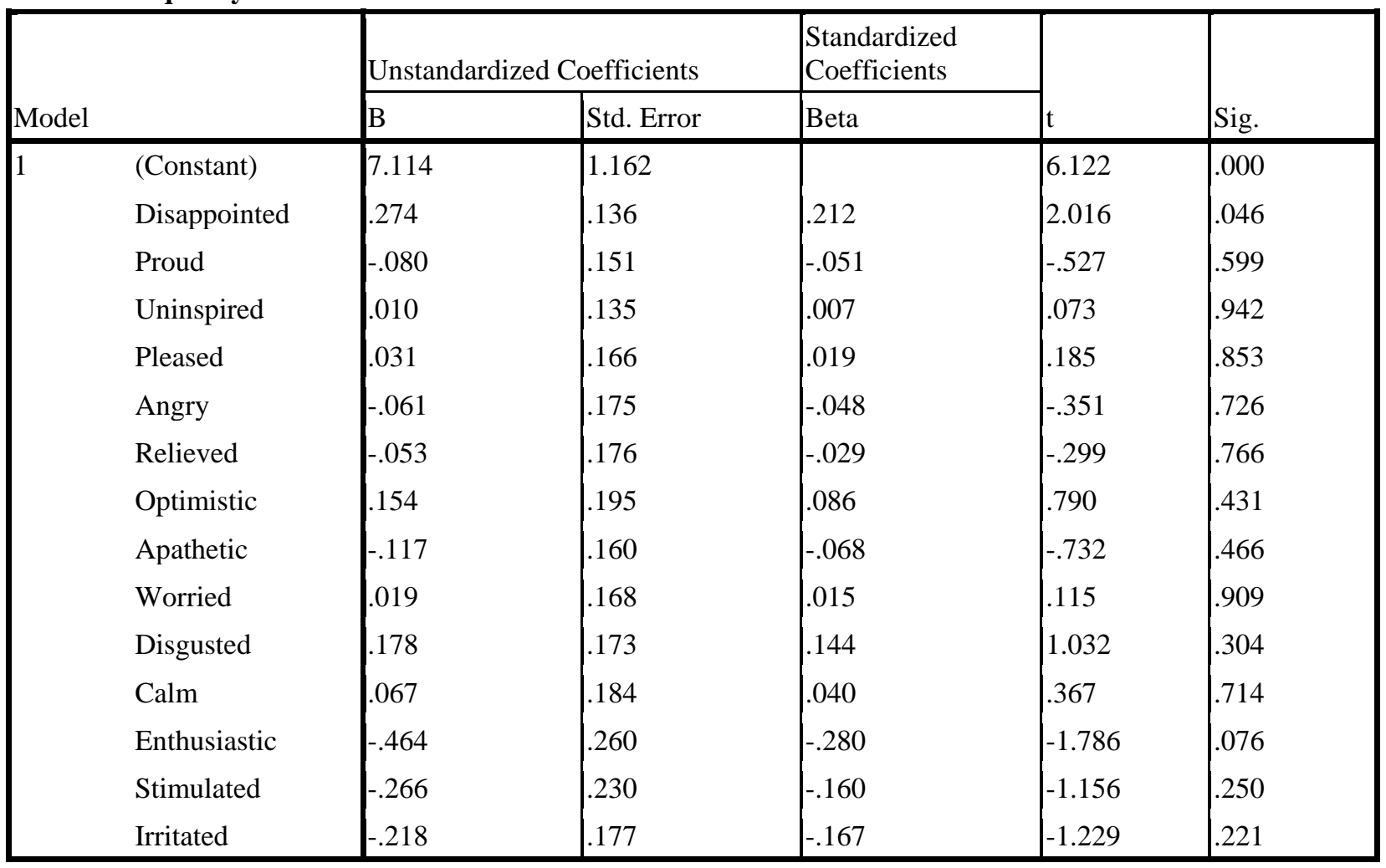

a. Dependent Variable: often

\section{LIMITATIONS AND DISCUSSION}

As with any study there are limitations to this study. First, the study examines primarily students and faculty rather than the population at large. Though this group is an especially strong user of social networking, results ought to be replicated across other locations to confirm the preliminary findings of the study. Though this group does represent a population of significant users, results may be different with non-students, non-faculty, or with other age groups. Another limitation is the sample size. Though sizable, the number of participants can be increased to improve reliability. Finally, the study only examines the use one aspect of personality, level of introversion/extraversion. There are other personality traits that could be tested.

\section{IMPLICATIONS FOR RESEARCHERS AND PRACTITIONERS}

Overall, it has been demonstrated that levels of extraversion/introversion do affect social networking. Practitioners can use the findings to tailor their technologies to address levels of this personality trait. In addition, researchers can use this study as a springboard to further studies of other personality traits. The emotional findings can be used by practitioners to improve their social networking offerings to facilitate trial, increase usage, and provide a more positive and productive social networking experience.

\section{CONCLUSION}

Overall, this study has provided significant influences on Social Networking trial, frequency of use, and amount of use. We see this as the start of an exploration of ways to increase and improve penetration of this valuable technology. Studies can be developed to confirm these findings with larger and more diverse sample groups, but 
preliminary findings suggest that Social Networking is subject to efforts to improve behavior through attention to the significant influencing variables of personality and emotions. Overall, this is a fertile research area that deserves further attention.

\section{REFERENCES}

1. Allen, C. T., Machleit, K. A., \& Kleine, S. S. (1992). A Comparison of Attitudes and Emotions as Predictors of Behavior at Diverse Levels of Behavioral Experience. Journal of Consumer Research, 18(4), 493-504.

2. Amichai-Hamburger, Y. \& Vinitzky, G. (2010). Social network use and personality. Computers in Human Behavior, 26(6), 1289-1295.

3. Amichai-Hamburger, Y., Wainapel, G., \& Fox, S. (2002). “On the Internet No One Knows I'm an Introvert”: Extraversion, Neuroticism, and Internet Interaction. CyberPsychology \& Behavior, 5(2), 125-128.

4. Bagozzi, R. P. (2007). The Legacy of the Technology Acceptance Model and a Proposal for a Paradigm Shift. Journal of the Association for Information Systems, 8(4), 244-254.

5. Boyd, D.M., \& Ellison, N.B. (2008). Social Network Sites: Definition, History, and Scholarship. Journal of Computer-Mediated Communication, 13(1), 210-230.

6. Brown, R. B. (2003). Emotions And Behavior: Exercises in Emotional Intelligence. Journal of Management Education, 27(1), 122-134.

7. Correa, T., Hinsley, A.W., \& de Zuniga, H.G. (2010). Who interacts on the Web?: The intersection of users' personality and social media use. Computers in Human Behavior, 26(2), 247-253.

8. Ehrenberg, A., Juckes, S., White, K.M. \& Walsh, S.P. (2008). Personality and self-esteem as predictors of young people's technology use. Cyberpsychology \& Behavior, 11 (6), 739-741.

9. Gefen, D., \& Keil, M. (1998). The Impact of Developer Responsiveness on Perceptions of Usefulness and Ease of Use: An Extension of the Technology Acceptance Model. The DATA BASE for Advances in Information Systems, 29(2), 35-49.

10. Goby, V.P. (2006). Personality and Online/Offline Choices: MBTI Profiles and Favored Communication Modes in a Singapore Study. CyberPsychology \& Behavior, 9(1), 5-13.

11. Harbaugh, E.R. (2010). The Effect of Personality Styles (Level of Introversion-Extraversion) on Social Media Use. The Elon Journal of Undergraduate Research in Communications, 1(2), 70-86.

12. Kwon, O., \& Wen, Y. (2010). An empirical study of the factors affecting social network service use. Computers in Human Behavior, 26(2), 254-263.

13. Lyons, W. (1978). Emotions and Behavior. Philosophy and Phenomenological Research, 38(3), 410-418.

14. Morahan-Martin, J. (1998). The Gender Gap in Internet Use: Why Men Use the Internet More Than Women A Literature Review. CyberPsychology \& Behavior, 1(1), 3-10.

15. Odell, P.M., Korgen, K.O., Schumacher, P., \& Delucchi, M. (2000). Internet Use Among Female and Male College Students. CyberPsychology \& Behavior, 3(5), 855-862.

16. Perlusz, S. (2004). Emotions and Technology Acceptance: Development and Validation of a Technology Affect Scale. International Engineering Management Conference Proceedings, 2, 845-847.

17. Peslak, Alan R. (2004). Emotions and team projects and processes, Team Performance Management, 11 (7/8), 251-262.

18. (2010, November 18). Review of the List of the Best Social Networking websites 2011. Retrieved April 11, 2011 from website: http://orangecopper.com/blog/list-of-the-best-social-networking-websites-2011

19. Ross, C., Orr, E.S., Sisic, M., Arseneault, J.M., Simmering, M.G., \& Orr, R.R. (2009). Personality and motivations associated with Facebook use. Computers in Human Behavior, 25(2), 578-586.

20. Shaw, T. (2004). The emotions of systems developers: an empirical study of affective events theory. Proceedings of SIGMIS'04, 124-126.

21. Teo, T. (2010). Gender differences in the intention to use technology: A measurement invariance analysis. British Journal of Educational Technology, 41(6), 120-123.

22. Teo, T.S.H., \& Lim, V.K.G. (2000). Gender differences in internet usage and task preferences. Behaviour \& Information Technology, 19(4), 283-295.

23. (2011, February 21). Twitter vs. facebook. Retrieved April 11, 2011 from TechStroke website: http://techstroke.com/twitter-vs-facebook.html 
Volume XII, No. 1, pp. 159-169, 2011

24. Weiser, E.B. (2000). Gender Differences in Internet Use Patterns and Internet Application Preferences: A Two-Sample Comparison. CyberPsychology \& Behavior, 3(2), 167-178.

25. Wilhelm, A. (2011, January 18). Internet Penetration Around The World Infographic]. Retrieved April 10, 2011 from website: http://thenextweb.com/shareables/2011/01/18/internet-penetration-around-the-world-infographic/

26. (2010, August 2). What Americans do Online: Social media And Games Dominate Activity. Retrieved April 9, 2011 from website: http://blog.nielsen.com/nielsenwire/online_mobile/what-americans-do-online-social-mediaand-games-dominate-activity/

27. (2010, May). Who's Online - Internet Demographics. Retrieved April 9, 2011 from Pew Research Center's Internet \& American Life Project website: http://www.pewinternet.org/Trend-Data/Whos-Online.aspx

28. Zywica, J., \& Danowski, J. (2008) The faces of Facebookers: Investigating social enhancement and social compensation hypotheses. Journal of Computer-Mediated Communication, 14 (1), 1-34. 